\title{
HEUTAGOGIA: O ENSINO SUPERIOR NO BRASIL E O MERCADO DE TRABALHO
}

\author{
Renata Coentrão Marques \\ Mestre em Psicologia (UCP) \\ recoentrao@hotmail.com \\ Cleia Zanatta Clavery Guarnido Duarte \\ Doutora em Psicologia Social (UERJ) \\ cleia.zanatta@ucp.br
}

\begin{abstract}
RESUMO
A aprendizagem vislumbra muitos caminhos a serem percorridos do professor até o aluno e vice-versa. Esta relação se entrelaça de tal forma que se deparam com situações comuns de dificuldade para sua reflexão. A heutagogia é um modelo de processo de aprendizagem muito difundido atualmente, principalmente quando se popularizou a educação a distância, modificando a vida social e as práticas de ensino quanto à proximidade do docente e do discente. As especificações cotidianas de entendimento de aprendizagem ultrapassam o material didático para se autogerenciarem. Este artigo teve como objetivo entrelaçar heutagogia, ensino superior e necessidades do mercado de trabalho no contexto brasileiro, dando um panorama da educação a distância e as preocupações que este estilo de aprendizagem traz. Uma revisão sistemática de artigos foi utilizada como metodologia de pesquisa a partir dos termos heutagogia, ensino superior e mercado de trabalho. Foram detectados 5 artigos sobre a temática que mostraram que a heutagogia estava relacionada ao ensino superior a distância, conseguindo reaproximar as pessoas à universidade, com rapidez, flexibilidade e aplicabilidade imediata, principalmente para os trabalhadores. A globalização trouxe para o contexto brasileiro muitos desafios e a necessidade de velocidade, o que levou a expansão desta aprendizagem principalmente para dentro da universidade que precisará se aprimorar para ensinar e produzir conhecimento científico e cultural inovador.
\end{abstract}

Palavras-chave: Heutagogia. Ensino superior. Mercado de trabalho

\section{HEUTAGOGY: HIGHER EDUCATION IN BRAZIL AND THE JOB MARKET}

\begin{abstract}
Learning envisions many ways to go from teacher to student and instead. This relationship interwines in such a way that common situations of difficulty for its reflection come across. Heutagogy is a model of the widespread learning process today, especially when distance education was popularized, changing social life and teaching practices regarding the proximity of teachers and students. The daily specifications of learning comprehension go beyond the didactic material to self-manage. The objective of this paper was to interwine heutagogy, higher education and job market needs in the Brazilian context, giving an overview of distance education and the concerns that this style of learning brings. A
\end{abstract}


systematic review of articles was used as a research methodology based on the terms heutagogy, higher education and the job market. Five articles were found on the subject that heutagogy was related to higher education at a distance, being able to bring people closer to the university, with speed, flexibility and immediate applicability, especially for workes. Globalization has brougth to the Brazilian context many challenges and the need for speed, with has led to the expansion of this learning especially within the university which will need to improve to teach and produce scientific and cultural knowledge innovative.

Keywords: Heutagogy. Higher educational. Job market 


\section{INTRODUÇÃO}

O ensino superior no Brasil, como em outras localidades do mundo, está passando por mudanças significativas pelo desenvolvimento da tecnologia da informação e pela imposição do mercado de trabalho que constantemente está em evolução e aplicando novos formatos de empreendimentos e formação de negócios (BALBACHEVSKY; SAMPAIO; ANDRADE, 2019; FISCHER; SCHAEFFER; VONORTAS, 2019).

Todas estas mudanças fazem parte da organização da sociedade e sua coexistência com táticas administrativas e sociológicas do capital, influenciando na cultura, racionalização do trabalho e ação social (FERNANDES et al., 2019; SCAGLIONE; MEYER JÚNIOR; MAMÉDIO, 2019).

O ensino e a aprendizagem mudaram de centrado no professor para centrado no aluno, novas técnicas de ensino surgiram e um estilo de aprendizagem chamado de heutagogia, pautado no aprendizado autodeterminado, se aprimora e junto com a tecnologia da informação torna o processo mais ativo (JAZEEL, 2016; BLASCHKE, 2012).

A heutagogia está muito associada ao ensino de educação a distância que se expandiu no Brasil e no mundo pela facilidade de chegar a vários locais, até mesmo remotos, pelo auxílio da tecnologia da informação. Na tecnologia está a chave para o que se conhece de mais moderno em termos de aprendizagem e inclusão digital (JONES; PENALUNA; PENALUNA, 2019).

Com o aparecimento de novas tecnologias da informação e comunicação houve maior integração das pessoas no processo educacional e propagação de conhecimentos, embora haja alguma resistência na expansão desta modalidade de ensino, muito difundida pelas universidades particulares e analisada por pensadores como democratizante (NASCIMENTO; VIEIRA, 2016).

A educação é uma área importante para o contexto social e as mudanças no formato de aprendizagem impostas pela sociedade, advindas da evolução tecnológica, confrontaram, até então, o que existia em termos de educação e ensino representadas pela pedagogia e a andragogia (CASTRO, 2016).

As distâncias geográficas reduziram e a tecnologia da informação e a internet fazem parte deste processo, aumentando a oferta de cursos a distância. A autonomia do estudante 
no uso dos recursos disponibilizados e na preparação do seu ciclo de atividades a serem cumpridas também difere do que se tinha antigamente (MEDEIROS; FARIA, 2003).

A sociedade industrial, desde sua origem, se transformou pelas expectativas de organização do trabalho de forma diferenciada e complexa devido ao próprio formato de contratação das pessoas para exercer as funções, trazendo para a atualidade novas formas de entendimento do trabalho (LI et al., 2019).

Os registros de ensino a distância apareceram no final do século XIX, mais precisamente em 1840 na Inglaterra, propiciadas por instituições particulares nos Estados Unidos e na Europa com o material didático enviado por correspondência. Na década de 70 houve a expansão dos cursos pelo rádio e televisão e em 80 vieram os áudios e vídeos por correspondência. Em 90 apareceram a internet e CD-room (ANDERSON; DRON, 2011; FARIA; SILVA, 2007). No Brasil, não há registros corretos do seu começo, mas segundo Chermann e Bonini (2000), entre 1922 e 1925, ocorreu um processo educativo na rádio, ligada à Roquette Pinto e Rádio Sociedade do Rio de Janeiro.

A construção de uma rede de comunicação por computadores apareceu na década de 1960 e a acessibilidade comercial da internet na década de 90. O primeiro navegador comercial surgiu em 94 (Netscape Navigator) e em 95 o Internet Explorer (CASTELLS, 2003).

Segundo a sinopse estatística do ensino superior no Brasil do Instituto Nacional de Estudos e Pesquisas Educacionais Anísio Teixeira (INEP), para 2018 foram 6.394.244 alunos matriculados nas universidades brasileiras, sendo 1.904 .554 para públicas e 4.489 .690 para as particulares na forma presencial. No formato a distância foram 2.056.511, sendo 172.927 para as públicas e 1.883 .584 para as particulares (INSTITUTO NACIONAL DE ESTUDOS E PESQUISAS EDUCACIONAIS ANÍSIO TEIXEIRA, 2019).

O ensino superior a distância faz uso de vários sistemas, ferramentas e estruturas no sentido de buscar desenvolver escolhas e habilidades dos alunos através do contato com o conteúdo pelas novas tecnologias ou materiais didáticos de suporte: e-mail, fóruns, chats, flexibilidade de horários para estudo e interatividade (SNOWDEN; HALSALL, 2014; BEVILAQUA; PELEIAS, 2013; BARNETT, 2011; DEAQUINO, 2007).

A educação superior, pelo desenvolvimento da tecnologia da informação, introduziu a heutagogia como um estilo de aprendizagem. O perfil do estudante caracterizará a aplicação mais desejável de estrutura e suporte oferecidos pelo ambiente virtual em decorrência das suas expectativas e atuações na sociedade atual (DEAQUINO, 2007). 
A heutagogia torna o professor um tutor por tirar dele a imposição de produção de conteúdo por aula; interações imediatas com os alunos em qualquer local, data e horário, com fóruns de discussões e e-mail para contato; rápidas soluções de problemas e afinidade com a realidade do aluno a partir de uma tecnologia móvel para participação, questionamento e colaboração (MANN et al., 2017; VELETSIANOS, 2010).

As empresas precisam de uma aprendizagem rápida, flexível, autônoma e que aprimore as habilidades dos funcionários (BELLAN, 2008). Desta forma, observa-se que a pedagogia volta-se para as crianças, a andragogia para o adulto e a heutagogia para grupos com necessidades mais específicas (ALMEIDA, 2003).

A autoaprendizagem, dentro da ótica de conhecimento compartilhado, utiliza da autodireção com base nas experiências cotidianas como saber. A informação é selecionada e transformada para um conhecimento robusto (ALMEIDA, 2003).

Pelo excesso de informação, a heutagogia discute o desenvolvimento individual, não se restringindo a relação ensino-aprendizagem, e como oferecê-lo em termos de conteúdo e modelo. O professor coloca a disposição os recursos e o estudante planeja seu percurso por um sistema de negociações que envolve argumentação, avaliação e decisão (BAPTISTA, 2011; BELLAN, 2008; HASE; KENYON, c2000).

Bellan (2008) apresenta conceitos e aplicações práticas para descobrir estilos, formatos de retenção e estratégias de aprendizagem (questionários, jogos e testes lógicos). As fontes de consulta ofertadas para os alunos são diversas, em vez de conteúdos programáticos, podendo selecioná-los e não usar todos, negociar as formas de avaliação como experiências de aprendizagem e não simples aferição do objetivo atingido, aceitandose o questionamento crítico (HASE; KENYON, c2000).

Este artigo teve como objetivo entrelaçar a concepção de heutagogia com o ensino superior e o mercado de trabalho brasileiro para se conhecer o que há sobre o estudo deste tipo de estilo de aprendizagem.

\section{MATERIAIS E MÉTODO}

Para a elaboração deste trabalho fez-se uma pesquisa na modalidade de revisão sistemática de artigos publicados por meios escritos em periódicos, permitindo conhecer o que já se estudou sobre o assunto, sintetizando pesquisas e levando a novos conhecimentos 
e discussões sobre o tema. Todo o fluxo do processo do levantamento está exposto na Figura 1.

Figura 1: Etapas para elaboração do artigo sobre heutagogia, ensino superior e mercado de trabalho

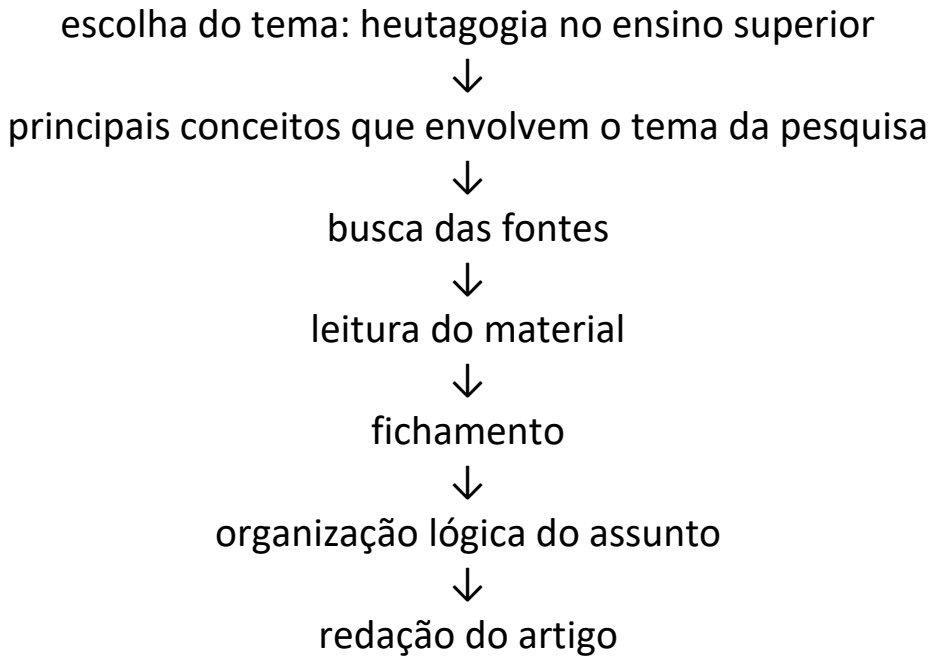

Fonte: Autor (2020).

Utilizou-se o idioma português, pesquisado com o auxílio dos descritores "heutagogia", "ensino superior" e "mercado de trabalho". O termo heutagogia deveria estar presente para identificação do estilo de aprendizagem. Os esforços foram concentrados nas publicações dos últimos quatro anos (2016-2019). Foi escolhido este período de tempo por ser considerado momento histórico de transição de 2 governos federais. Os critérios de inclusão deveriam ser ainda artigos completos, disponibilizados no formato online e revisados por pares.

As buscas foram feitas nas bases de dados Google Acadêmico, Scielo, Lilacs (Literatura Latino Americana e do Caribe em Ciências da Saúde), Science Direct e Portal de Periódicos da Coordenação de Aperfeiçoamento de Pessoal de Nível Superior (CAPES).

Como pré-seleção conferiu-se o título e o resumo do artigo para determinar os trabalhos que apresentavam os descritores estipulados. Em seguida, foi feita a leitura completa dos artigos. 
Para apresentação dos dados encontrados elaborou-se uma tabela com título do artigo, autores, nome da revista, ano de publicação, tipo de estudo e resultados dos trabalhos selecionados.

\section{RESULTADOS E DISCUSSÃO}

As transformações no mercado do trabalho, como a precarização e o desemprego decorrentes da lógica neoliberal, refletem nos efeitos do financiamento do capital em sua expansão, suscitando terceirizações, baixa proteção ao trabalhador e de alta rotatividade nos postos de atividades, com tensão entre capital e trabalho (SILVA; SOUSA, 2019).

Para ultrapassar os obstáculos advindos do mercado de trabalho, os indivíduos estão buscando se aperfeiçoar e encontrar soluções que os tornem o mais próximo das possibilidades de emprego e/ou cargos que os coloquem em posições mais confortáveis de atuação profissional (GÓIS; RIBEIRO; MOTA, 2019).

O termo heutagogia surgiu de dois pensadores Stewart Hase e Chris Kenyon (c2000), tendo origem grega: heuta (auto), agein (conduzir) e logos (ciência), definindo-se como a ciência da aprendizagem autodeterminada ou conduzida. Ela advém da evolução natural da andragogia, onde o professor ainda é o centro da ação da aprendizagem, mas não conseguindo abarcar a tecnologia da informação quanto a sua rapidez e quantidade de fluxo de conhecimento produzido para o público.

Segundo Halsall, Powell e Snowden (2016), sua base está nas perspectivas de Rogers (1951), Argyris e Schon (1974), Carr e Kemmis (1986), Knowles (1973), Lave e Wenger (1991) e Stephenson e Yorke (1998).

Rogers (1951) falou da aprendizagem como algo inato, em que o desejo de aprender é um processo interno controlado pelos próprios alunos, e o professor é um facilitador da aprendizagem. Quando se aprende algo novo, a sua identidade se modifica e um novo olhar se apresenta (BARNETT, 2011). Criam-se, desta forma, possibilidades de habilidades e vivências relevantes e, através de incentivos, o aluno se tornará um sujeito construtor da aprendizagem, organizado em torno de atividades e experiências, em uma abordagem holística e autêntica. O lugar do aluno está no centro do aprendizado, em que ele orienta o que deve ser aprendido, com um tutor que é o facilitador da aprendizagem e não se restringindo a um currículo pré-estabelecido (MAY; POWELL, 2008; SWAN, 2001). 
Rogers (1951 apud HASE; KENYON, c2000) apontou que a aprendizagem está centrada no aluno em que: toda pessoa possui o desejo de aprender e tende a realizá-lo; o professor é o agente facilitador da aprendizagem; e existe, por parte do aluno, certa resistência à aprendizagem significativa, pela modificação do self que ela proporciona.

O conceito de aprendizagem de laço duplo de Argyris e Schön (1974) também contribuiu com a criação do termo heutagogia em que propuseram utilizar a reflexão e o questionamento (valores e suposições) dos sujeitos para resolver um problema ou uma situação. Desta forma, aprende-se o novo já relacionado com o conhecimento acumulado anteriormente.

Segundo Carr e Kemmis (1986), a educação era uma atividade prática, no sentido de mudar os alunos conforme os objetivos almejados. A causa dos problemas educacionais enfrentados pelos professores seria a contradição entre a realidade e a teoria que eles têm sobre ela.

Knowles (1973) criou a andragogia baseando-se em que os adultos se motivavam através de interesses e necessidades e que a fonte de aprendizagem era a experiência. $\mathrm{O}$ professor determinava o que aprender e o adulto escolhia como aprender. Considerado o pai da andragogia, Knowles focou esta ciência nos adultos, apoiado em quatro pilares: independência do aluno em continuar o aprendizado além da fala do professor; as experiências usadas para construção da aprendizagem; conhecimento vinculado à prática social e as atividades cotidianas; e aplicabilidade da aprendizagem imediatamente (DEAQUINO, 2007). A aprendizagem autônoma compreendia em um processo centrado no aluno em que as experiências pessoais eram utilizadas para o professor se tornar um recurso do estudante (KNOWLES, 1990).

A teoria da aprendizagem situada de Lave e Wenger (1991) dizia que aprendizagem era um aspecto integral e inseparável da prática social em que lugares, participação de comunidades e possibilidades de mudança faziam parte do aprendizado.

Stephenson e Yorke (1998) acreditavam que pessoas capazes eram aquelas que sabiam aprender, demonstrando eficácia e competência em situações desconhecidas. A capacidade era o processo de aquisição de habilidades, conhecimentos, ética e julgamento para resolver problemas e competência era o processo de empenho no presente para realizações futuras no trabalho. 
Hase e Kenyon (c2000) caracterizaram heutagogia como o estudo da aprendizagem autodirigida (o aluno toma a iniciativa na sua formação a partir da análise e percepção de suas necessidades) e não da autoaprendizagem (forma de aprender por si só). O professor partilhava o conhecimento para o aluno ser autônomo e fazer suas próprias escolhas no que se refere à aprendizagem, com alto envolvimento no processo de ensino e reflexão. $\mathrm{O}$ aluno determinava o que ele aprenderia em função do desenvolvimento de suas capacidades e aspirações vocacionais.

Eles defendiam que havia ênfase no holismo, no eu, na capacidade, na comunidade, nas necessidades da sociedade, foco na aprendizagem reflexiva, valorização da experiência e a interação, principalmente para um mundo com mudanças rápidas, exigindo flexibilidade e atualização constante para a inserção profissional (SNOWDEN; HALSALL, 2014).

O estilo de aprendizagem proposto pela heutagogia é condizente com a sociedade atual em que a informação aparece rapidamente e em volume considerado expressivo e a formação do aluno deve se adequar para suprir o cotidiano e o mercado de trabalho. $O$ aprender precisa estar ligado ao fazer e há necessidade de existência de práticas flexíveis para a aprendizagem quanto ao tempo e espaço (BAPTISTA, 2011; HASE; KENYON, c2000).

A heutagogia possui uma estrutura em sintonia com a sociedade contemporânea, onde os alunos têm seus interesses de aprendizado e práticas incentivados dentro da comunidade. A interdependência dos eventos no trabalho e a capacidade de prevê-los alimentam a vontade de aprender (HASE; KENYON, 2013; HASE; KENYON, 2007).

O mundo do trabalho requer rapidez, tecnologia, acessibilidade, flexibilidade e habilidades para um ambiente dinâmico, não se aceitando mais o conhecimento baseado em disciplinas fragmentadas (BARNETT, 2014). A heutagogia foi escolhida pela comunidade de tecnologia da educação, levando a centralização na rede. Os alunos são autônomos e autodeterminados, adquirindo competências e capacidades para o mercado de trabalho (BLASCHKE, 2012).

As desvantagens que podem ocorrer com a adoção deste estilo de aprendizagem são (BARNETT, 2007):

- $\quad$ risco epistemológico: ao seguir seus interesses, ao aprender o que querem e ao criarem seu próprio currículo, os alunos podem ter uma distorção de compreensão de um campo ou perspectiva; 
- $\quad$ risco prático: com baixas habilidades práticas para responder efetivamente a esse estilo, os alunos deixam de desenvolver e progredir em novas habilidades;

- $\quad$ risco pedagógico: pode interferir no desenvolvimento de um "espaço para o ser", moldando a identidade do aluno.

Segundo Snowden e Hardy (2012), a heutagogia está baseada no ensinoaprendizado para soluções e na aprendizagem assistida por tutores que incentivam a negociar como, o que e quando aprender, levando em conta a explicitação de problemas vivenciados nas experiências e contextos de trabalho.

O aluno se torna independente do professor (VELETSIANOS, 2010), trazendo maturidade e autonomia (CANNING, 2010). A maturidade gera menos controle do instrutor e flexibilidade no curso (CANNING; CALLAN, 2010). Os alunos se tornam confiantes, competentes para atuarem profissionalmente e questionadores da realidade (BANGURA, 2005).

A tutoria, dentro da heutagogia, se propõe a orientar, apoiar, diminuir a ansiedade, motivar, navegar e familiarizar o aluno com a universidade e as estruturas que se apresentam para a aprendizagem, visando ao desenvolvimento de competências e habilidades para o sucesso profissional no mercado de trabalho (SNOWDEN; HARDY, 2012; KERRY; MAYES, 1995).

O professor é um facilitador que orienta para a autodireção, reflexão, crítica, pesquisas de ação e utilização das ferramentas, saindo do saber absoluto para o compartilhamento de conhecimentos que podem ser usufruídos na prática cotidiana (CANNING; CALLAN, 2010).

A heutagogia é um estilo compatível com as necessidades rápidas e melhorias constantes do mundo e do sistema capitalista de produção por trazer a construção de um novo espaço educacional e interativo a qualquer hora e lugar que se deseje estudar e por se poder manter-se ativo no mercado de trabalho (BLASCHKE; HASE, 2019).

\subsection{Processo de seleção dos artigos para análise}

Durante a preparação deste trabalho pode-se constatar a escassez de material publicado sobre o assunto. Com as buscas feitas, foram encontrados 12 artigos, utilizando o operador bolleano AND, acrescentando-se os seguintes critérios de inclusão: produções 
científicas no idioma Português e no período de 4 anos (2016-2019). Neste primeiro refinamento utilizou-se apenas 2 descritores: heutagogia e ensino superior. Posteriormente, utilizou-se como critério de inclusão apenas os artigos que possuíam simultaneamente os 3 descritores (heutagogia, ensino superior e mercado de trabalho), excluindo-se 7 artigos, totalizando 5 artigos no final. Após a leitura na íntegra destes artigos, apenas 5 possuíam estas características (Figura 2).

Figura 2: Fluxograma do processo de seleção dos artigos sobre a temática heutagogia, ensino superior e mercado de trabalho no período de 2016 a 2019

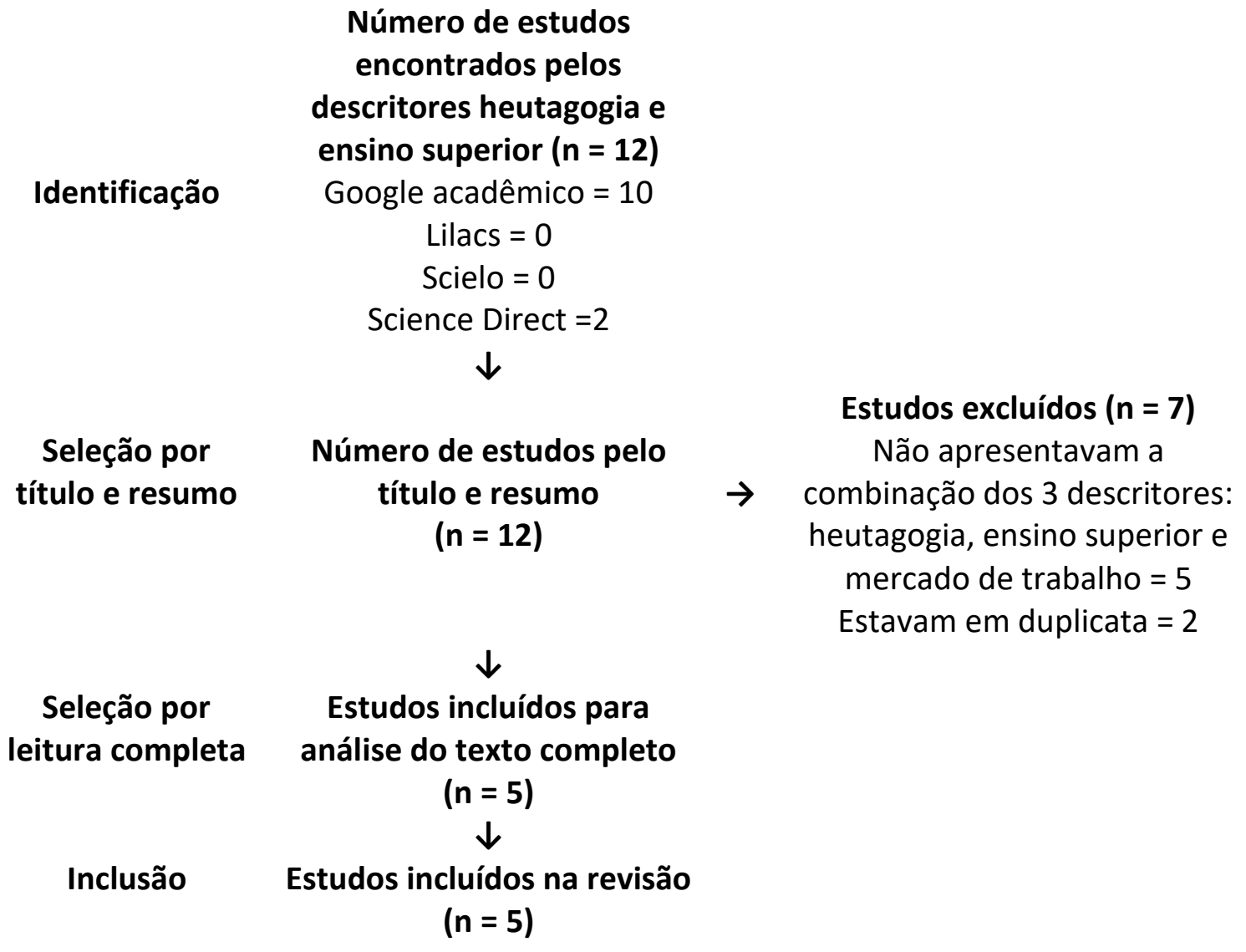

Fonte: Autor (2020).

Finalizou-se a contagem verificando que 5 artigos em periódicos contemplavam a temática. Com estes materiais foram compiladas todas as informações necessárias que caracterizassem heutagogia, ensino superior e mercado de trabalho. Os dados do levantamento estão apresentados no Quadro 1, contendo o título do artigo, autores, nome 
da revista, ano de publicação, tipo de estudo e resultados encontrados. Cada artigo encontra-se identificado por um número para melhor organização.

Quadro 1: Artigos selecionados na revisão sobre a temática heutagogia, ensino superior e mercado de trabalho no período de 2016 a 2019

\begin{tabular}{|c|c|c|c|c|c|}
\hline$n^{\circ}$ & Título do artigo & Autores & Revista & Ano & $\begin{array}{l}\text { Tipo de } \\
\text { estudo }\end{array}$ \\
\hline 1 & $\begin{array}{l}\text { Cursos online de } \\
\text { especialização na estrutura } \\
\text { da pós-graduação no } \\
\text { Brasil. }\end{array}$ & $\begin{array}{l}\text { GOZZI, M. P.; } \\
\text { KENSKI, V. M. }\end{array}$ & $\begin{array}{l}\text { Eccos Revista } \\
\text { Científica, n. 39, p. } \\
\text { 87-100, jan./abr. }\end{array}$ & 2016 & qualitativo \\
\hline
\end{tabular}

Resultados: Os profissionais estavam percebendo a necessidade de formação continuada e encontravam na EaD as facilidades e vantagens relativas à flexibilidade espaço-temporal; por outro lado, essa expansão exigia que mais professores estivessem capacitados para atuar nesses cursos.

No campo profissional, a EaD foi considerada apropriada para atender à demanda por pessoas mais qualificadas diante de novos processos de produção, novas profissões e novos espaços de construção do saber. Os servidores de instituições governamentais, os profissionais da iniciativa privada e os profissionais autônomos, inclusive, tinham no EaD um excelente meio para o aprimoramento de seus conhecimentos (GOZZI; KENSKI, 2016)

\begin{tabular}{|l|l|l|l|l|l}
2 & $\begin{array}{l}\text { O perfil do aluno da } \\
\text { educação a distância e seu } \\
\text { estilo de aprendizagem }\end{array}$ & $\begin{array}{l}\text { GODOI, M. A.; } \\
\text { OLIVEIRA, S. M. S. } \\
\text { S. }\end{array}$ & $\begin{array}{l}\text { Revista Científica em } \\
\text { Educação a a } \\
\text { Distância, v. 6, n. 2, } \\
\text { p. 76-91 }\end{array}$ & quantitativo \\
\hline
\end{tabular}

Resultados: A maioria era do sexo feminino, com idade de 33 anos e renda de três salários mínimos. Os alunos, em sua maioria, estudaram em escola pública, trabalhavam e sabiam usar a tecnologia. Demonstrou-se o caráter flexível (espaço $\mathrm{x}$ tempo) e inclusivo da modalidade para a formação em articulação com as responsabilidades profissionais do mercado (GODOI; OLIVEIRA, 2016).

\begin{tabular}{|l|l|l|l|l|l|}
\hline 3 & $\begin{array}{l}\text { Estilos de aprendizagem e } \\
\text { ensino a distância na } \\
\text { perspectiva da inclusão }\end{array}$ & $\begin{array}{l}\text { SOUZA, S. S. S.; } \\
\text { ARAGON, G. T. }\end{array}$ & $\begin{array}{l}\text { Revista EaD em } \\
\text { Foco, v. 8, n. 1, p. 01- } \\
11, \text { jun. }\end{array}$ & qualitativo \\
\hline
\end{tabular}

Resultados: Observou-se que o aluno desta modalidade possuía características próprias, destacando-se a experiência profissional onde o mercado de trabalho incentivava esta busca por aprimoramento e, ao mesmo tempo, a falta de condições socioeconômicas para estudar. Igualmente importante era o desenvolvimento da autonomia e da motivação nos estudos pelo aluno adulto nessa modalidade educacional.

Os estilos de aprendizagem foram considerados importantes instrumentos a serem pensados nos processos de ensino-aprendizagem integrados à modalidade de ensino a distância, sendo estes instrumentos de política pública educacional de democratização ao acesso à educação (SOUZA; ARAGON, 2018)

\begin{tabular}{l|l|l|l|l|l}
\hline 4 & $\begin{array}{l}\text { Autonomia e internet: } \\
\text { binômio necessário para o } \\
\text { curso a distância de } \\
\text { tecnologia em hotelaria do } \\
\text { IFCE }\end{array}$ & R. A.; LIMA, J. C. & $\begin{array}{l}\text { Conexão, Ciência e } \\
\text { Tecnologia, v. 12, n. } \\
\text { 3, p. 40-51, dez. }\end{array}$ & quantitativo \\
\hline
\end{tabular}

Resultados: O essencial não era encher o aluno de informações, mas que estes possuíssem capacidade de selecionar, interpretar e elaborar as mensagens conforme suas pretensões (salário, primeiro emprego, autonomia e realização da aprendizagem em qualquer local e tempo) em uma aprendizagem autodirecionada em que o aluno seria gestor e programador dos seus estudos. 
Os alunos utilizavam todas as ferramentas disponíveis na plataforma digital, além de outras como email, Whatsapp, facebook e estavam satisfeitos com os resultados quanto às exigências do curso (ESMERALDO; LIMA, 2018).

\begin{tabular}{|l|l|l|l|l|l|}
\hline 5 & O processo de & PINHO, J. C.; & Competência: & 2019 & qualitativo \\
& democratização do ensino & SOUSA, J. C.; & Revista de Educação & & \\
lato sensu a & SILVA, A. W. P.; & Superior do Senac - & & \\
distância à luz da & SILVA, P. M. M.; & RS, v. 12, n. 1, p. 01- & & \\
percepção de alunos de & EL-AOUAR, W. A. & 10, jul. & & \\
um curso de & & & & \\
pós-graduação da & Universidade Aberta do & & & & \\
Brasil no Ceará & & & & \\
\hline
\end{tabular}

Resultados: Foi destacado pelos alunos a capacitação na área em que atuavam como oportunidade de se manter à frente na questão de títulos em concursos e obtenção de incentivos financeiros para a permanência no mercado de trabalho, exigência de constante aperfeiçoamento para um bom desempenho na carreira, bem como uma boa prestação de serviços à sociedade.

O sistema de educação a distância foi considerado um meio de aproximação do conhecimento a pessoas com difícil acesso aos cursos presenciais de ensino, garantindo com isso a mesma oportunidade de capacitação para indivíduos de localidades diversas.

Os resultados apontaram para o processo de democratização, revelando fatores positivos como autonomia, comodidade e flexibilidade do processo de aprendizagem, que garantia a todos o direito de estudarem onde, quando e como quiserem e a universalidade da aprendizagem. Entretanto, as dificuldades eram tirar dúvidas e a lentidão em absorver conteúdos quando comparadas aos cursos presenciais. (PINHO et al., 2019)

Fonte: Autor (2020).

\subsection{Análise dos artigos}

Conforme exposto na Tabela 1, os artigos empíricos compilados eram qualitativos, com revisão de literatura (artigo 1 e 3) e entrevista (artigo 5), e quantitativos com o uso de questionários como instrumentos de acesso às informações necessárias para a pesquisa (artigos 2 e 4).

Quanto à procedência geográfica de produção dos artigos, o artigo 1 era proveniente do Estado de São Paulo, o artigo 2 de Minas Gerais, o artigo 3 do Rio de Janeiro e os artigos 4 e 5 do Ceará. Assim, os estudos focados pelas pesquisas emergiram das regiões Sudeste e Nordeste do Brasil.

Os artigos selecionados descreviam a educação no ensino superior, mais especificamente a educação a distância, trazendo como ponto de estudo a intenção de inserção no mercado de trabalho (artigos 1, 2, 3, 4 e 5), tendo mais relevância a exigências deste mercado e flexibilidade do espaço e tempo (artigo 1), perfil do aluno, acessibilidade, a visão de responsabilidade profissional e uso da estrutura tecnológica disponibilizada (artigo 
2), uso das tecnologias e a inclusão do aluno com necessidades especiais diante de suas expectativas profissionais (artigo 3), uso da tecnologia e pretensões futuras profissionais (artigo 4) e acesso e qualidade do curso online que poderiam possibilitar promoção profissional e incentivos financeiros (artigo 5).

No artigo 1 foi discutido o contexto dos cursos de especialização no Brasil na modalidade a distância online, fomentados pelas mudanças no mercado de trabalho. São destacadas a definição de pós-graduação, leis específicas que a regem (BRASIL, 2007; BRASIL, 2001; BRASIL, 1996), estatísticas de oferta dos cursos e concluintes, sua relação com o mercado de trabalho e a flexibilidade com a questão tempo e espaço para o estudo.

Akhmetshin et al. (2019) ao estudar 426 alunos de universidade públicas e privadas e 35 empresários da Rússia perceberam os mesmos resultados que o artigo 1, especificando que era uma forma de educação relativamente nova, que havia expectativa dos alunos em ter um emprego de sucesso e prontidão para competir no mercado, mas constataram certa desconfiança dos empregadores por acharem o conhecimento insuficiente.

A pesquisa sobre cursos de especialização aprofunda as discussões sobre quais são as necessidades do mercado de trabalho que influenciam na escolha da profissão e especificamente para aquela área de conhecimento.

Conforme especificado no artigo 1 (GOZZI; KENSKI, 2016, p. 92), os profissionais buscaram os cursos por perceberem as imposições de atualização, pois o mercado de trabalho "exige um estado de permanente formação, qualificação e capacitação".

Os autores verificaram que os fatores que levaram os alunos a escolherem a educação a distância foram: a distância geográfica que gerava custos de transporte e hospedagem, jornada laboral, o mercado de trabalho que exigia novos processos de produção, novas profissões e novos espaços de construção do saber, disponibilidade de métodos de ensino inovadores e flexíveis para a demanda e atingir mercados de ensino distantes.

Estas colocações são apoiadas por Litto e Formiga (2009) que informaram que muitos municípios não possuem estrutura para instalação de uma faculdade, dificultando o acesso ao ensino superior, assim como, pessoas mais velhas puderam retomar os estudos, em uma inclusão social e digital. Gorz (2005) e Zuenzer (2002) falaram que o mundo do trabalho apresenta uma realidade excludente e o trabalhador passou a ser o responsável pela sua empregabilidade, atualizando-se e adaptando-se ao posto de trabalho. 
O fomento da especialização está largamente associado à relação de dependência com o mercado de trabalho, visto que as pessoas especificam o que gostariam, dentro do currículo disponibilizado e cumprido na graduação, de continuar investindo seu tempo dentro da carreira profissional. Ao priorizar uma área da profissão estão focando em se manter naquele cargo por mais tempo e dele retirar sua autorrealização (KUCHARSKI; BASSO, 2016).

Quanto mais próximo da realidade vivenciada pelo aluno dentro do que se propõe no currículo com relação à especialização, melhor e mais aceitável será a opinião sobre o ensino a distância. Se esta experiência proporcionar um controle maior sobre a profissão, nos moldes que cada indivíduo considerar proveitoso, mais irão se identificar e conseguir aplicar em suas realidades (WARMLING et al., 2018).

O artigo 2 teve a pretensão de caracterizar o perfil dos alunos de graduação a distância e o estilo de aprendizagem mais favorável para a formação, abarcando as três definições de estilo de aprendizagem (pedagogia, andragogia e heutagogia), as motivações para estudar, como a profissionalização e as responsabilidades do aluno no contexto do trabalho, e as habilidades com as tecnologias.

Neste artigo, Godoi e Oliveira (2016) ao aplicarem um questionário em 235 alunos de graduação a distância descobriram que a maioria era casada, pagava seu próprio curso, estudava no período de folga, advinha da escola pública, tinha computador de uso pessoal, com acesso a internet, conhecia a tecnologia e tinha foco em suas responsabilidades como profissionais inseridos no mercado de trabalho e que necessitavam de constante atualização.

Estes dados demonstram que, como já citado por Litto e Formiga (2009), as pessoas estão se aprimorando ou iniciando sua graduação fora do período estipulado como apropriado para a idade, com suas experiências pessoais e com capacidade de manipulação fácil do computador e plataformas digitais.

Este perfil sinaliza para o aspecto social e econômico do ensino a distância para as tendências e exigências da sociedade que pede sujeitos qualificados, informados, atentos para aprender e com crescente produtividade. O ensino a distância é democratizante quanto ao conhecimento, mas é uma modalidade de aprendizagem que pode servir para os modelos de reprodução capitalistas (JERÔNIMO, 2018). 
A graduação possui uma motivação mais direta com as habilidades que o aluno conseguiu enxergar em si mesmo para poder desenvolver como meta de carreira, ainda revestida de incertezas e expectativas. Alguns já estão no mercado de trabalho e querem o diploma para certificar as pessoas, de forma oficial, que são capazes de executar determinada função (MAMEDE; ABBAD, 2018).

A heutagogia, neste caso, transporá os problemas de tempo e espaço para realizar o que o aluno caracterizou como vocação e este estilo de aprendizagem suprirá os desejos.

Lee, Choi e Cho (2018) ao estudarem 200 estudantes universitários na Coréia perceberam que o ensino a distância foi apontado como uma excelente oportunidade de acesso ao ensino superior, ao mercado de trabalho e promessas de uma vida melhor.

No artigo 3 o olhar sobre a inclusão das pessoas com necessidades especiais esteve presente e como a educação a distância poderia contribuir. São contempladas as ferramentas tecnológicas e os ambientes virtuais voltados para este público, no sentido do desenvolvimento profissional e das competências e habilidades necessárias para o mercado de trabalho.

Como resultado tem-se que o uso de tecnologias apropriadas e viáveis pode aprimorar a taxa de sucesso e auxiliar na mobilidade, comunicação e aprendizagem, observando as particularidades do indivíduo e suas expectativas profissionais.

O desenho universal para aprendizagem deverá conter elementos dos princípios da diversidade, identidade e diferença. As particularidades e acessibilidade devem andar juntas para este contexto e os professores precisam escolher diferentes funções sensoriais nas tecnologias para adaptação às necessidades próprias de cada estudante (BURGSTAHLER, 2009).

A inclusão na era digital direciona-se para favorecer o momento de aprendizagem com linguagem apropriada, recursos e espaço produtivo para o estudante, permitindo sua autonomia, raciocínio e o lúdico em porcentagens adequadas conforme a necessidade que se apresenta (GUIMARÃES; SOUSA; LIMA, 2019).

No artigo 4 os objetivos eram determinar os recursos tecnológicos como instrumentos para garantir a autonomia de ensino a distância, a percepção dos alunos quanto ao seu uso e suas pretensões profissionais. Foram apurados os elementos facilitadores e os obstáculos para a utilização. 
Assim como no artigo 2, os autores fizeram um levantamento dos alunos, mas acrescentaram o nível de conhecimento sobre as plataformas pelos professores percebido pelos discentes. A maioria dos alunos era do sexo feminino, de 24 a 36 anos, solteira, trabalhava, possuía computador em casa com banda larga na residência, mas usava o celular para acessar o ambiente virtual de aprendizagem, não possuindo dificuldades no uso da tecnologia e estava satisfeita. Para os estudantes, os professores sabiam utilizar os recursos tecnológicos.

Segundo Bevilaqua e Peleias (2013) a satisfação pode estar ligada aos recursos que os estudantes observaram quando entraram no ambiente virtual de aprendizagem como: materiais didáticos, interação dos conhecimentos com professores e outros estudantes, atualização profissional e perspectivas para o mundo do trabalho, conciliação entre trabalho, família e estudo e valor das mensalidades. Mais uma vez a democratização é apontada como vantagem, mas as questões de cunho reprodutivistas da sociedade para o mercado de trabalho precisam ser analisadas (JERÔNIMO, 2018).

Halili (2019) ao estudar a situação da Malásia quanto ao uso de avanços tecnológicos no ensino e aprendizagem observou que a educação a distância é um fenômeno da penetração digital no dia a dia e que abraçaria a quarta revolução industrial com impressão 3D, computação em nuvem, holograma, biometria, tela LCD multitoque, internet das coisas, inteligência artificial, big data e código QR para fins educacionais.

A autonomia pesquisada no artigo revela a capacidade de ser disciplinado e ter consciência do poder de realização das atividades. A heutagogia propiciava e estimulava que o aluno pudesse tomar conhecimento de si mesmo, obstáculos e oportunidades, desenvolvesse seu potencial crítico sobre a sociedade e sobre si mesmo e qual seu empenho para conquistar o que estabeleceu como perspectiva de futuro.

Este entrelaçamento entre o presente vivenciado no trabalho, na família e na sociedade e a visão do futuro implica este tipo de estilo de aprendizagem como mais adequado para suprir as necessidades do que agora se apresentava para colheita de frutos mais na frente do tempo, em termos de atividade profissional, vínculos familiares e sociais.

O artigo 5 objetivou avaliar a democratização do ensino lato sensu por meio do programa Universidade Aberta do Brasil (UAB) da Universidade Estadual do Ceará, a luz da percepção dos alunos de um curso de pós-graduação. Permeou suas análises sobre as 
avaliações das políticas públicas de educação e o ensino a distância como meio de aproximação do conhecimento a pessoas com dificuldade de acesso a cursos presenciais.

Segundo Nascimento e Vieira (2016) a UAB pode estar inserida na administração central ou em unidades acadêmicas e a forma de gerenciar o ensino de educação a distância diferencia-se para cada local.

Os autores através de entrevista com 6 alunos do curso de gestão pública verificaram que escolheram o curso de especialização online por ser compatível com a formação acadêmica inicial, comodidade e tempo para fazer. Os alunos deixaram claro a relação direta do aprendizado a distância com a possibilidade que esta modalidade daria de conseguir títulos acadêmicos para concursos públicos, promoção profissional e incentivos financeiros. Quanto à avaliação do curso, os tutores foram considerados eficazes e com acessibilidade boa, mas havia excesso de leitura. Como perspectivas futuras, os estudantes colocaram que desejavam continuar estudando.

Grau-Valldosera, Minguillón e Blasco-Moreno (2019) ao pesquisarem estudantes na Espanha observaram que a intenção de continuidade no ensino a distância se baseava no nível de satisfação com a experiência educacional, motivações para estudar e ter um emprego.

O tutor, para execução do seu trabalho, precisa conhecer as mídias existentes, os formatos de curso, projeto pedagógico e motivar. Ao aluno cabe ser disciplinado e determinado. A orientação deve focar nos materiais didáticos e outras pesquisas, tirar dúvidas sobre os instrumentos e tecnologias utilizados (GONZALEZ, 2005).

Os cursos de especialização a distância podem ser encaixados com o entendimento de necessidade de aprendizagem que o mercado de trabalho estabelece e no que o aluno estipula como aprimoramento do seu conhecimento. O tempo é um fator importante no somatório de atividades que o adulto precisa fazer. Neste contexto, também entra o tutor que dispensará ao estudante as atenções necessárias para permanecer no curso e progredir em cada etapa da aprendizagem (STURMER et al., 2020).

As universidades devem adaptar seu escopo ao seu público quando se trabalha, principalmente, com educação a distância, devido as diferentes capacidades cognitivas e de conhecimento, área geográfica e mercados de trabalho específicos (BIELSCHOWSKY, 2018).

\section{CONSIDERAÇÕES FINAIS}


As universidades no Brasil estão se adaptando às necessidades demonstradas pelos alunos e que se vinculam aos sistemas de produção estabelecidos pela sociedade com relação ao trabalho, como legislação, regulamentos, salários e progressões, que fazem surgir ritmos diferenciados de saber-fazer.

O ensino superior envolve-se neste processo considerando sua capacidade de influenciar na ação social e propor transformações pela possibilidade de acesso ampliado, melhoria da educação e desenvolvimento regional por atingir locais distantes.

Nesta pesquisa foi possível perceber que as pessoas estavam buscando o ensino superior a distância dentro do estilo da heutagogia para tentarem aprimorar sua aprendizagem, investindo para que melhor se coloquem no mercado de trabalho e mantenham e/ou evoluam em seus postos de atividade. Os resultados encontrados caracterizaram um perfil de aluno mais velho, trabalhador, envolvido com um núcleo familiar e que enxergava neste estilo de aprendizagem a oportunidade de mudanças concretas de qualidade de vida.

As dimensões que legitimam o ensino superior, como competência, qualidade, acessibilidade, estrutura e outros indicadores, foram encontradas nestes artigos, reforçando a racionalidade técnica e os conhecimentos aprendidos atrelados a incerteza do mercado de trabalho, as escolhas pelo conhecimento e o desenvolvimento da tecnologia.

Esta flexibilidade da educação pela heutagogia possibilita a abertura de espaço de socialização e compartilhamento de experiências e potenciais pelos fóruns e chats com a sala virtual, oportunizando a proximidade, interesses, problemas comuns, objetivos e visões de cada origem dos participantes.

\section{REFERÊNCIAS}

AKHMETSHIN, E. M. et al. Entrepreneurial skills development through distance learning. Journal of Entrepreneurship Education, [S.I.], v. 22, n. 1S p. 1-10, 2019. Disponível em: https://www.abacademies.org/articles/entrepreneurial-skills-development-throughdistance-learning-7967.html. Acesso em: 3 dez. 2019.

ALMEIDA, M. E. B. Educação a distância na internet: abordagens e contribuições dos ambientes digitais de aprendizagem. Educação e Pesquisa, São Paulo, v. 29, n. 2, p. 327-340, jul./dez. 2003. Disponível em: https://www.scielo.br/scielo.php?pid=S151797022003000200010\&script=sci_abstract\&tlng=pt. Acesso em: 2 dez. 2019. 
ANDERSON, T.; DRON, J. Three generations of distance education pedagogy. International Review of Research in Open and Distance Learning, [S.I.], v. 12, n. 3, p. 80-97, Mar. 2011. Disponível em: http://www.irrodl.org/index.php/irrodl/article/view/890. Acesso em: 3 dez. 2019.

ARGYRIS, C.; SCHÖN, D. A. Theory in practice: increasing professional effectiveness. San Francisco: Jossey Bass, 1974.

BALBACHEVSKY, E.; SAMPAIO, H.; ANDRADE, C. Y. Expanding access to higher education and its (limited) consequences for social inclusion: the brazilian experience. Social Inclusion, [S.I.], v. 7, n. 1, p. 7-17, 2019. Disponível em: https://www.ssoar.info/ssoar/bitstream/handle/document/61103/ssoar-socialinclusion2019-1-sampaio_et_al-

Expanding_access_to_higher_education.pdf?sequence=1\&isAllowed=y. Acesso em: $3 \mathrm{dez}$. 2019.

BANGURA, A. K. Ubuntugogy: an African educational paradigm that transcends pedagogy, andragogy, ergonagy and heutagogy. Journal of Third World Studies, [S.I.], v. 22, n. 2, p. 1318, Sep. 2005.

BARNETT, R. Conditions of flexibility: securing a more responsive higher education system. New York: HEA, 2014.

BARNETT, R. The coming of the ecological university. Oxford Review of Education, [S.I.], v. 37, n. 4, p. 439-455, 2011.

BARNETT, R. A will to learn: being a student in an age of uncertainty. Maidenhead: McGraw Hill/OUP, 2007.

BAPTISTA, M. N. M. M. S. O professor - tutor: perfil e funções. Poiésis, Tubarão, v. 4, n. 7, p. 145-155, jan./jun. 2011.

BELLAN, Z. Heutagogia: aprenda a aprender mais e melhor. Santa Bárbara d'Oeste: Z3 Ideias, 2008.

BEVILAQUA, S.; PELEIAS, I. R. "Em vez de dar o peixe, ensine a pescar": a heutagogia e a sua relação com os métodos de aprendizagem em cursos EaD no Brasil. In: Encontro de Ensino e Pesquisa em Administração e Contabilidade, 4., 2013, Brasília, DF. [Anais] Brasília, DF: EnEPQ, 2013. Disponível em: http://www.anpad.org.br/admin/pdf/EnEPQ148.pdf. Acesso em: 3 dez. 2019.

BIELSCHOWSKY, C. E. Qualidade na educação superior a distância no Brasil: onde estamos, para onde vamos?. Revista EaD em Foco: Revista Científica em Educação a Distância, [S.I.], v. 8, n. 1, p. 01-26, 2018. Disponível em:

http://abed.org.br/arquivos/qualidade_educacao_superior_distancia_carlos_biel_abr_2018. pdf. Acesso em: 4 dez. 2019. 
BLASCHKE, L. M.; HASE, S. Heutagogy and digital media networks: setting students on the path to lifelong learning. Pacific Journal of Technology Enhanced Learning, [S.I.], v. 1, n. 1, p. 1-14, 2019. Disponível em:

https://www.researchgate.net/publication/333942664_Heutagogy_and_digital_media_net works_Setting_students_on_the_path_to_lifelong_learning. Acesso em: 4 dez. 2019.

BLASCHKE, L. M. Heutagogy and lifelong learning: a review of heutagogical practice and selfdetermined learning. The International Review of Research in Open and Distributed Learning, [S.I.], v. 13, n. 1, p. 56-71, Jan. 2012. Disponível em: http://www.irrodl.org/index.php/irrodl/article/view/1076. Acesso em: 4 dez. 2019.

BRASIL. Lei $\mathbf{n}^{\circ}$. 9.394, de 20 de dezembro de 1996. Estabelece as diretrizes e bases da educação nacional. Brasília, DF: Presidência da República, 1996. Disponível em: http://www.planalto.gov.br/ccivil_03/leis/19394.htm. Acesso em: 3 dez. 2019.

BRASIL. Conselho Nacional de Educação. Câmara de Educação Superior. Resolução nº 1, de 8 de setembro de 2007. Estabelece normas para o funcionamento de cursos de pósgraduação lato sensu, em nível de especialização. Brasília, DF: Associação Brasileira de Mantenedoras de Ensino Superior, 2007. Disponível em: https://abmes.org.br/arquivos/legislacoes/Res_CES_001_2007_06_08.PDF. Acesso em: 4 dez. 2019.

BRASIL. Resolução CNE/CES n. 1, de 3 de abril de 2001. Estabelece normas para o funcionamento de cursos de pós-graduação. Diário Oficial da União: seção 1, Brasília, DF: 9 abr. 2001. Disponível em:

http://portal.mec.gov.br/seed/arquivos/pdf/tvescola/leis/CES0101.pdf. Acesso em: 4 dez. 2019.

BURGSTAHLER, S. Universal design in education: principles and applications. Seattle: University of Washington, 2009.

CANNING, N.; CALLAN, S. Heutagogy: spirals of reflection to empower learners in higher education. Reflective Practice, [S.I.], v. 11, n. 1, p. 71-82, 2010.

CANNING, N. Playing with heutagogy: exploring strategies to empower mature learners in higher education. Journal of Further and Higher Education, [S.I.], v. 34, n. 1, p. 59-71, 2010.

CARR, W.; KEMMIS, S. Becoming critical: education, knowledge and action research. London: The Palmer Press, 1986.

CASTELLS, M. A galáxia da internet: reflexões sobre a internet, os negócios e a sociedade. Rio de Janeiro: Jorge Zahar, 2003.

CASTRO, R. F. Autorregulação da aprendizagem no ensino superior a distância: o que dizem os estudantes? REBES: Revista Brasileira de Ensino Superior, [S.I.], v. 2, n. 2, p. 15-26, abr./jun. 2016. Disponível em: 
https://www.researchgate.net/publication/308041216_Autorregulacao_da_Aprendizagem_ no_Ensino_Superior_a_Distancia_O_que_Dizem_os_Estudantes. Acesso em: 2 dez. 2019.

CHERMANN, M.; BONINI, L. M. Educação a distância: novas tecnologias em ambientes de aprendizagem pela internet. São Paulo: Universidade Braz Cubas, 2000.

DEAQUINO, C. T. E. Como aprender: andragogia e as habilidades de aprendizagem. São Paulo: Pearson, 2007.

ESMERALDO, L. R. A.; LIMA, J. C. F. Autonomia e internet: binômio necessário para o curso a distância de tecnologia em hotelaria do IFCE. Conexão, Ciência e Tecnologia, Fortaleza, CE, v. 12, n. 3, p. 40-51, dez. 2018.

FARIA, M. A.; SILVA, R. C. S. Ead: o professor e a inovação tecnológica. Revista Brasileira de Aprendizagem Aberta e a Distância, São Paulo, v. 6, p. 1-8, dez. 2007. Disponível em: http://seer.abed.net.br/edicoes/2007/2007_EaD_o_professor_e_a_inovacao_Monica_Faria. pdf. Acesso em: 4 dez. 2019.

FERNANDES, E. et al. Educational data mining: predictive analysis of academic performance of public school studentes in the capital of Brazil. Journal of Business Research, [S.I.], v. 94, p. 335-343, Jan. 2019.

FISCHER, B. B.; SCHAEFFER, P. R.; VONORTAS, N. S. Evolution of university-industry collaboration in Brazil from a technology upgrading perspective. Technological Forecasting \& Social Change, v. 145, p. 330-340, Aug. 2019.

GODOI, M. A.; OLIVEIRA, S. M. S. S. O perfil do aluno da educação a distância e seu estilo de aprendizagem. Revista EaD em Foco: Revista Científica em Educação a Distância, v. 6, n. 2, p. 76-91, 2016. Disponível em:

https://eademfoco.cecierj.edu.br/index.php/Revista/article/view/383. Acesso em: 3 dez. 2019.

GÓIS, L. S.; RIBEIRO, M. M.; MOTA, L. M. Educação para o mercado: ideário capitalista que conforma a educação profissional brasileira. Rev. HISTEDBR On-line, Campinas, SP, v.19, p.120, 2019. Disponível em:

https://periodicos.sbu.unicamp.br/ojs/index.php/histedbr/article/view/8654528/21043. Acesso em: 3 dez. 2019.

GONZALEZ, M. Fundamentos da tutoria em educação a distância. São Paulo: Avercamp, 2005.

GORZ, A. O imaterial: conhecimento, valor e capital. São Paulo: Anablume, 2005.

GOZZI, M. P.; KENSKI, V. M. Cursos online de especialização na estrutura da pós-graduação no Brasil. Eccos: revista científica, [S.I.], n. 39, p. 87-100, jan./abr. 2016. 
GRAU-VALLDOSERA, J.; MINGUILLÓN, J.; BLASCO-MORENO, A. Returning after taking a break in online distance higher education: from intention to effective re-enrollment. Journal Interactive Learning Environments, v. 27, n. 3, p. 307-323, 2019.

GUIMARÃES, I. J. B.; SOUSA, M. R. F.; LIMA, I. F. Educação a distância como ferramenta de inclusão social e digital: um estudo de caso com alunos da UFPBVIRTUAL. Encontro Bibli: Revista Eletrônica de Biblioteconomia e Ciência da Informação, Florianópolis, v. 24, n. 56, p. 1-19, set./dez. 2019. Disponível em:

https://www.researchgate.net/publication/335710793_Educacao_a_distancia_como_ferra menta_de_inclusao_social_e_digital. Acesso em: 4 dez. 2019.

HALILI, S. H. Technological advancements in education 4.0. The Online Journal of Distance Education and e-Learning, [S.I.], v. 7, n. 1, p. 63-69, Jan. 2019. Disponível em: http://www.tojdel.net/journals/tojdel/articles/v07i01/v07i01-08.pdf?report=reader. Acesso em: 4 dez. 2019.

HALSALL, J. P.; POWELL, J. L.; SNOWDEN, M. Determined learning approach: implications of heutagogy society based learning. Journal Cogent Social Sciences, [S.I.], v. 2, n. 1, p. 1-11, 2016. Disponível em:

https://www.tandfonline.com/doi/full/10.1080/23311886.2016.1223904?scroll=top\&needA ccess=true. Acesso em: 2 dez. 2019.

HASE, S.; KENYON, C. Self determined learning: heutagogy in a action. London: Bloomsbury, 2013.

HASE, S.; KENYON, C. Heutagogy: a child of complexity theory. Complicity: An International Journal of Complexity and Education, [S.I.], v. 4, n. 1, p. 111-118, 2007.

HASE, S.; KENYON, C. From andragogy to heutagogy. Melbourne: RMIT, c2000. Disponível em:https://webarchive.nla.gov.au/awa/20040812230212/http://pandora.nla.gov.au/pan/10 088/20020813/ultibase.rmit.edu.au/Articles/dec00/hase2.htm. Acesso em: 2 dez. 2019.

INSTITUTO NACIONAL DE ESTUDOS E PESQUISAS EDUCACIONAIS ANÍSIO TEIXEIRA. Sinopses estatísticas da educação superior: graduação. Portal INEP, Brasília, DF, 20 de outubro de 2015. Disponível em: http://portal.inep.gov.br/web/guest/sinopses-estatisticas-daeducacao-superior. Acesso em: 2 dez. 2019.

JERÔNIMO, I. C. Os sujeitos e suas representações: a educação a distância e os dizeres dos alunos acerca da modalidade. Estudos Linguísticos, São Paulo, v. 47, n. 3, p. 744-757, 2018. Disponível em: https://revistas.gel.org.br/estudos-linguisticos/article/view/1945/1402. Acesso em: 2 dez. 2019.

JONES, C.; PENALUNA, K.; PENALUNA, A. The promise of andragogy, heutagogy and academagogy to enterprise and entreneurship education pedagogy. Education + Training, [S.I.], v. 61, n. 9, p. 1170-1186, 2019. Disponível em: https://repository.uwtsd.ac.uk/1130/. Acesso em: 2 dez. 2019. 
JAZEEL, A. M. Efectiveness of heutagogy integrated e-content modules on understanding osmosis among science studentes in colleges of education in Sri Lanka. International Educational Applied Scientific Research Journal, [S.I.], v. 1, n. 1, p. 36-39, Oct. 2016. Disponível em: http://ieasrj.com/journal/index.php/ieasrj/article/view/12. Acesso em: 3 dez. 2019.

KERRY, T.; MAYES, A. S. Issues in mentoring. London: Routledge, 1995.

KUCHARSKI, M. V. S.; BASSO, V. H. Estudo da evasão no curso de especialização em tecnologias, comunicação e técnicas de ensino da UAB - UTFPR. Revista Intersaberes, [S.I.], v. 11, n. 23, p. 346-363, mai./ago. 2016. Disponível em:

https://www.uninter.com/intersaberes/index.php/revista/article/view/1041. Acesso em: 2 dez. 2019.

KNOWLES, M. S. Andragogo versus pedagogo. USA: Association Press, 1990.

KNOWLES, M. The adult learner: a neglected species. Madison: American Society for Training and Development, 1973.

LAVE, J.; WENGER, E. Situated learning: legitimate peripheral participation. New York: Cambridge University Press, 1991.

LEE, K.; CHOI, H.; CHO, Y. Becoming a competent self: a developmental process of adult distance learning. The Internet and Higher Education, [S.I.], v. 41, p.1-16, Apr. 2018.

Disponível em:

https://www.researchgate.net/publication/329788769_Becoming_a_competent_self_A_dev elopmental_process_of_adult_distance_learning. Acesso em: 3 dez. 2019.

LI, W. et al. Interactive relationships between industrial, urban, agricultural, information and green development. Energy \& Environment, [S.I.], v. 30, n. 6, p. 991-1009, 2019.

LITTO, F. M.; FORMIGA, M. M. M. Educação a distância: o estado da arte. São Paulo: Pearson Education do Brasil, 2009.

MAMEDE, W.; ABBAD, G. S. Objetivos educacionais de um mestrado profissional em saúde coletiva: avaliação conforme a taxonomia de Bloom. Educação \& Pesquisa, São Paulo, v. 44, p. 1-21, 2018. Disponível em: https://www.scielo.br/scielo.php?pid=S1517-

97022018000100309\&script=sci_abstract\&tlng=pt. Acesso em: 2 dez. 2019.

MANN, S. et al. Designing for heutagogy: na independent learning pathway approach. Scope: Flexible Learning, v. 2, p. 59-70, 2007-2017. Disponível em:

https://www.thescopes.org/assets/Uploads/b525f63386/SCOPE-Flexible-Learning-2-Web11-Mann-etal.pdf. Acesso em: 4 dez. 2019.

MAY, T.; POWELL, J. L. Situating social theory. Maidenhead: McGraw Hill, 2008. 
MEDEIROS, M. F.; FARIA, E. T. Educação a distancia: cartografias e movimento. Porto Alegre: EDICURPRS, 2003.

NASCIMENTO, J. P. R.; VIEIRA, M. G. Os desafios da institucionalização do ensino superior na modalidade a distância: a visão dos gestores de uma universidade federal. Ensaio: Avaliação e Políticas Públicas em Educação, Rio de Janeiro, v. 24, n. 91, p. 308-336, abr./jun. 2016. Disponível em: https://www.scielo.br/scielo.php?pid=S0104-

40362016000200308\&script=sci_abstract\&tlng=pt. Acesso em: 3 dez. 2019.

PINHO, J. C. et al. Acesso e qualidade das pós-graduações ofertadas por meio da educação a distância (ead). Competência: Revista de Educação Superior do Senac - RS, [S.I.], v. 12, n. 1, p. 01-10, jul. 2019. Disponível em: http://seer.senacrs.com.br/index.php/RC/article/view/697. Acesso em: 3 dez. 2019.

ROGERS, C. Client-centred therapy: its current practice, implications and theory. London: Constable, 1951.

SCAGLIONE, V. L. T.; MEYER JÚNIOR, V.; MAMÉDIO, D. F. Improvisation in higher education management: coping with complexity and organizational dynamics. Global Journal of Flexible Systems Management, [S.I.], v. 20, p. 291-302, 2019.

SILVA, M. L.; SOUSA, R. A. D. Trabalho e educação no contexto do ensino superior e a formação do assistente social. RIAEE: Revista Ibero-Americana de Estudos em Educação, Araraquara, v. 14, n. 2, p. 559-572, abr./jun. 2019. Disponível em:

http://oaji.net/articles/2020/8101-1598330287.pdf. Acesso em: 3 dez. 2019.

SNOWDEN, M.; HALSALL, J. Community development: a shift in thinking towards heutagogy. International Journal of Multi Disciplinary Comparative Studies, [S.I.], v. 1, n. 3, p. 81-91, 2014. Disponível em: http://eprints.hud.ac.uk/id/eprint/24758/. Acesso em: 4 dez. 2019.

SNOWDEN, M.; HARDY, T. Peer mentorship and positive effects on student mentor and mentee retention and academic success. Widening Participation and Lifelong Learning, $\mathrm{v}$. 14, p. 76-92, Winter 2012. Disponível em: http://eprints.hud.ac.uk/id/eprint/16921/. Acesso em: 4 dez. 2019.

SOUZA, S. S. S.; ARAGON, G. T. Estilos de aprendizagem e ensino a distância na perspectiva da inclusão. Revista EaD em Foco: Revista Científica em Educação a Distância, [S.I.], v. 8, n. 1, p. 1-11, jun. 2018.

STEPHENSON, J.; YORKE, M. Capability and quality in higher education: teaching and learning in higher education. London: Kogan Page, 1998.

STURMER, G. et al. Perfil dos profissionais da atenção primária à saúde, vinculados ao curso de especialização em saúde da família UMA-SUS no Rio Grande do Sul. Revista

Conhecimento Online, Novo Hamburgo, ano 12, v. 1, p. 4-26, jan./abr. 2020. Disponível em: https://www.researchgate.net/publication/338353478_PERFIL_DOS_PROFISSIONAIS_DA_AT 
ENCAO_PRIMARIA_A_SAUDE_VINCULADOS_AO_CURSO_DE_ESPECIALIZACAO_EM_SAUDE_ DA_FAMILIA_UNA-SUS_NO_RIO_GRANDE_DO_SUL. Acesso em: 2 dez. 2019.

SWAN, K. Virtual interaction: design factors affecting student satisfaction and perceived learning in asynchronous online courses. Distance Education, [S.I.], v. 22, n. 2, p. 306-331, 2001. Disponível em:

https://www.american.edu/library/technology/blackboard/upload/swan-article.pdf. Acesso em: 2 dez. 2019.

VELETSIANOS, T. Emerging technologies in distance education. Edmonton: Athabasca University Press, 2010.

ZUENZER, A. Z. Conhecimento e competências no trabalho e na escola. Boletim Técnico do SENAC, [S.I.], v. 28, n. 2, p. 1-10, mai./ago. 2002. Disponível em:

http://www.bts.senac.br/index.php/bts/article/view/539. Acesso em: 4 dez. 2019.

WARMLING, D. et al. Aproximando saberes e experiências à distância: relato da tutoria de um curso de especialização. Revista Salud Pública, [Bogotá], v. 20, n. 1, p. 132-137, 2018. Disponível em: http://www.scielo.org.co/scielo.php?script=sci_abstract\&pid=S012400642018000100132\&lng=en\&nrm=iso\&tlng=pt. Acesso em: 3 dez. 2019. 